\title{
Luminescence of Dipole-centers in ZnSe crystals
}

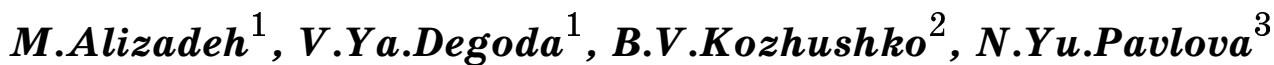 \\ ${ }^{1}$ T. Shevchenko National University of Kyiv, \\ 64 Volodymyrs'ka Str., 01601 Kyiv, Ukraine \\ ${ }^{2}$ Institute of Physics, National Academy of Sciences of Ukraine, \\ 46 Nauky Ave., 03028 Kyiv, Ukraine \\ ${ }^{3}$ National Pedagogical Dragomanov University, \\ 9 Pyrogova Str., 01601 Kyiv, Ukraine
}

Received December 12, 2016

\begin{abstract}
It is proposed a model of recombination luminescence center on which the two opposite mechanisms of recombination, electron and hole recombination, are implemented. Such a center of luminescence is observed in ZnSe crystals and causes the luminescence of a wide band with the maximum at about $1.92 \mathrm{eV}(630 \mathrm{~nm})$. It is performed comparison of some characteristics of this center with the characteristics of the center of luminescence which is a point defect and provides the maximum at of $1.27 \mathrm{eV}(970 \mathrm{~nm})$. It is shown that the external electric field and temperature have different impacts on the intensity and spectral positions of the maxima of these bands.

Keywords: center of recombination, point defects and complex defects, X-ray luminescence, photoluminescence, electric field, zinc selenide.

Предложена модель рекомбинационного центра свечения, на котором могут реализовываться одновременно два противоположных механизма рекомбинации - электронный и дырочный. Такой центр свечения, возможно, наблюдается в кристаллах ZnSe и обусловливает широкую полосу с максимумом при 1,92 eV (630 нм). Выполнены сравнения некоторых характеристик этого центра с характеристиками центра свечения, который является точечным дефектом и обусловливает полосу свечения с максимумом при $1,27 \mathrm{eV}$ (970 нм). Показано, что внешнее электрическое поле и температура по-разному влияют на интенсивности и спектральные положения максимумов этих полос.
\end{abstract}

Люмінесценція Dipole-центрів у кристалах ZnSe. M.Алізадеx, В.Я.Дегода, Б.В.Кожушко, Н.Ю.Павлова.

Запропоновано модель рекомбінаційного центру свічення, на якому можуть реалізовуватися одночасно два протилежних механізми рекомбінації - електронний i дірковий. Такий центр свічення, напевно, спостерігається у кристалах ZnSe i обумовлює широку смугу з максимумом при $1,9 \mathrm{eV}$ (630 нм). Виконано порівняння деяких характеристик цього центру із характеристиками центру свічення, який є точковим дефектом і обумовлює смугу свічення з максимумом при 1,28 eV (970 нм). Показано, що зовнішне електричне поле і температура по-різному впливають на інтенсивності та спектральні положення максимумів цих смуг.

\section{Introduction}

Zinc selenide ( $\mathrm{ZnSe})$ is a wide band gap (WBG) semiconductor, which is one of the well-known materials of the group $\mathrm{A}_{2} \mathrm{~B}_{6}$. High-resistance crystals of ZnSe are the most promising for use as ionizing radiation detectors, because typically they have bandgap on 
the order of $2.8 \mathrm{eV}$ and, therefore, can be operated at the higher ambient temperatures $[1,2]$. In addition, currently $\mathrm{ZnSe}$ is widely used as a material for manufacture of optical lenses and windows in IR region of the electromagnetic spectrum and in counters for the detection of $\gamma$ radiation by scintillation method [3-6]. It is, first and foremost, causes interest of researchers to zinc selenide.

Recently it was found an interesting feature in the ZnSe crystals [7]: in recombination center which produces luminescence with the maximum at of $1.92 \mathrm{eV}$ two mechanisms of recombination at X-ray excitation $(T=85 \mathrm{~K})$ are observed. That is, the defect of structure which wasn't recharged in quantum state can be localized in their environment such as electron and hole. The luminescence is observed only after localization in it the free charge carrier of the opposite charge. In the result exciton-impurity complex is created, which goes to an excited electronic state of the luminescence center. Next, this center passes from the excited state to the ground state with emission of a quantum of light (photon). At the same time, the same samples of ZnSe are logged luminescence of another point defect in the IR region of the electromagnetic spectrum (band with the maximum at of $1.27 \mathrm{eV})$. Moreover, luminescence from the both centers is clearly observed in phosphorescence and thermally stimulated luminescence after X-ray excitation as with 8 and $85 \mathrm{~K}$. In the result, there is an objective: to propose a model of the center, which can explain the possibility of realization of both mechanisms of recombination (electron and hole) in the one center of recombination. Obviously, such a center of recombination can't be a point of defect $(P)$. As the scheme of electronic levels and their point of symmetry do not allow simultaneous calculation of energy levels $P^{-}$and $P^{+}$in the band gap, there is the condition $E\left(P^{-}\right)-E\left(P^{+}\right)>E_{g}$. Also it can't be donor-acceptor pairs (DAP) since their luminescence in $\mathrm{ZnSe}$ is well known [8] and it is located in the shorter wavelength region of the spectrum than the band of luminescence of $1.92 \mathrm{eV}$. Also it should be considered, the DAP resulting from the interaction of independent donor and acceptor impurities when their concentration exceeds $10^{15} \mathrm{~cm}^{-3}$. But at the lower concentrations the donor and acceptor impurities are isolated. Based on the DAP nature it is impossible to imagine the simultaneous realization of the both mechanisms of re- combination on them. Since the ZnSe crystals have two dominant bands of luminescence in different spectral regions and due to the fundamentally different centers, it is logical to compare them in some spectral characteristics in terms of their similarities.

\section{Experimental}

We investigated specially undoped ZnSe single crystals (which were grown after pretreatment of the charge) with the aim of obtaining samples with the minimum concentration of impurities and structural point defects. For such crystals the maximum resistivity reached the values of $10^{12}$ $10^{14} \Omega \cdot \mathrm{cm}$ at room temperature. Trials were performed of X-ray luminescence (XRL) and photoluminescence (PL) at temperatures of $8,85,295$ and $410 \mathrm{~K}$ and the influence of external electric field on luminescence intensity was investigated. The samples of $\mathrm{ZnSe}$ by resistive method sprayed on 3-layer metal electrical contacts (two parallel strips with a size of $1 \times 5 \mathrm{~mm}^{2}$ at a distance of $5 \mathrm{~mm}$ from each other), which were connected to the DC stabilized power supply with adjustable voltage value in the range of 0-1000 V. The sample was placed in a cryostat, which allowed to conduct studies at different temperatures in the range of 8-500 K. To obtain the XRL spectra of the samples excited by the integral radiation flux from the X-ray tube BXV-7 (Re, $20 \mathrm{kV}, 25 \mathrm{~mA}, 130 \mathrm{~mm}$ ) through a beryllium window in the cryostat. And the photoluminescence was excited by illuminating the sample with light from seven light emitting diodes (LED) UF 300 (zones-zone excitation) through a quartz window in the cryostat. Luminescence spectra were recorded using monochromator MDR-2 and photomultiplier tubes PMT-and PMT 106-83 (with cooling system of photocathode). All obtained spectra were corrected for spectral sensitivity of registration system. To determine the spectral positions of the maxima of the bands the spectra were transferred from the scale of the wavelength $(\mathrm{nm})$ in the scale of energy quanta $(\mathrm{eV})$ taking into account the spectral radiation density.

\section{Results and discussion}

\subsection{Spectra of luminescence}

Spectra of X-ray luminescence (XRL) at different temperatures are shown in Fig. 1. Note that at $8 \mathrm{~K}$ in the spectra there are not observed either edge luminescence or luminescence of donor-acceptor pairs. At the 
high temperatures $(410 \mathrm{~K})$, due to the effect of thermal extinction of the luminescence, intensity of the XRL is falling so heavily that it becomes impossible to register the spectrum. At the same time, the obtained PL spectra were almost similar to the XRL spectra. PL spectrum was able to register at $410 \mathrm{~K}$ and found that at this temperature there is only one greatly extended the short wavelength band. It should be noted that the ratio of the intensities of the bands at of $1.92 \mathrm{eV}$ and $1.27 \mathrm{eV}$ is different in different ZnSe crystals, and the quantity ratio is changed by more than an order of magnitude. This means that defects are formed independently from each other, and their concentration is determined by various factors in the process of the single crystals growing.

Thus, in the XRL spectra two wellknown [9-13] broad bands with maxima at $630 \mathrm{~nm}$ (of $1.92 \mathrm{eV}$ ) and $970 \mathrm{~nm}$ (to $1.27 \mathrm{eV}$ ) are dominated. They are recombination luminescence bands, as clearly seen in the spectral composition of phosphorescence (at 8 and $85 \mathrm{~K}$ ), and also in the spectral composition of the thermally stimulated luminescence. Analysis shows that any point defect (structural defect or impurity, which becomes the center of recombination of crystal may implement only one mechanism of recombination either electronic (recombination of free electron with the positively recharged center recombination), or hole (recombination of free holes with negatively recharged by the recombination center). You also have to remember that all types of recombination centers and the mechanism of exciton recombination can additionally be implemented, namely: localization and subsequent recombination of an exciton at the centre of the glow. But in the wide-gap semiconductors $A_{2} B_{6}$ the binding energy of the exciton does not exceed several tens of $\mathrm{meV}$ and recombination of the excitons on the lattice defects is practically not observed at temperatures above $50 \mathrm{~K}$. It should be noted that even at temperatures of liquid helium in many of the dominant crystal there is a recombinant glow, especially when excited by the high-energy quanta of $\mathrm{X}$-rays.

Previously, it was found that at $85 \mathrm{~K}$ subject to X-ray excitation on the luminescence recombination center, which causes the luminescence band at $630 \mathrm{~nm}$ simultaneously both mechanisms of recombination are implemented [7]. That is, the recombination center can localize in its environment (li-

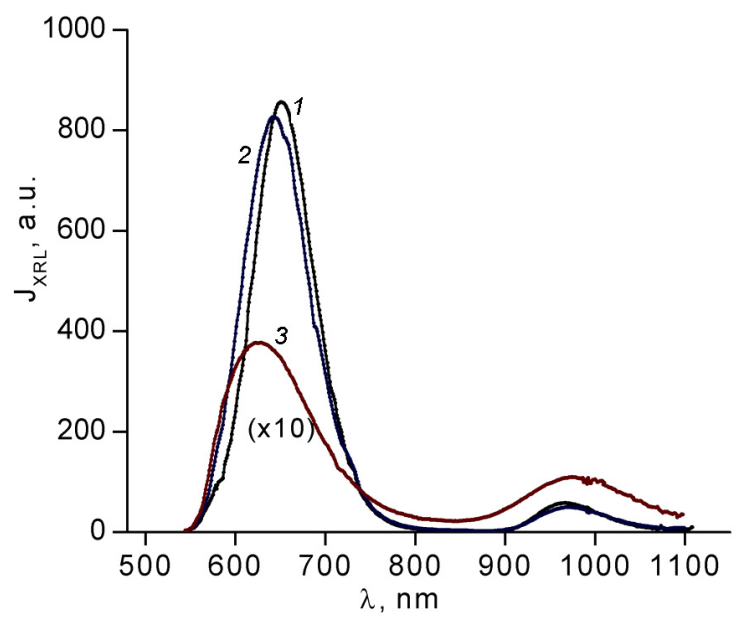

Fig. 1. Characteristic spectra of X-ray luminescence of monocrystalline $\mathrm{ZnSe}$ in different temperatures: $8 \mathrm{~K}(1)$; $85 \mathrm{~K} \mathrm{(2)}$ and $295 \mathrm{~K}(3)$.

gands) as an electron and a hole, but the luminescence is only observed after localization of opposite sign of charge carrier in free media. This raises the intermediate exciton-impurity state with the transition to the excited electronic States of the center of the glow. Further, there is spontaneous electronic transition of the center to the ground state with the emission of fluorescent photons.

Such a center of recombination in $\mathrm{ZnSe}$ can be integrated with defect $\mathrm{V}_{\mathrm{Zn}} \mathrm{Te}_{\mathrm{Se}}[14-$ 17], which forms negatively charged zinc vacancy $\mathrm{V}_{\mathrm{Zn}}$ and positively charged $\mathrm{Te}_{\mathrm{Se}}$. In addition, such center can have an asymmetric dipole $\mathrm{X}_{\mathrm{Te}} \mathrm{Zn}_{i}$, where $\mathrm{X}_{\mathrm{Te}}$ - atom substitution of tellurium in the chalcogenide of sublattice crystal $Z n S e$. And $Z n_{i}$ positive charge exceeds the negative charge of tellurium in the position of substitution. If such complex joins the negatively charged vacancy $V_{Z n}$, then forms defect complex which becomes $\mathrm{Zn}_{i} \mathrm{~V}_{\mathrm{Zn}} \mathrm{Te}_{\mathrm{Se}}$ quadrupole.

The center of the glow, which provides the appearance in the spectrum the band with maximum at $970 \mathrm{~nm}$, causes by point defects a vacancy of selenium [18-20] or an admixture of copper [21].

Thus, in the high-resistance crystals of $\mathrm{ZnSe}$ there are dealing with two types of dominant defects: complex dipole moment (the band at $630 \mathrm{~nm}$ ) and point (band at $970 \mathrm{~nm}$ ). Obviously, these different types of defects will be different in reaction to temperature and external electric field. 

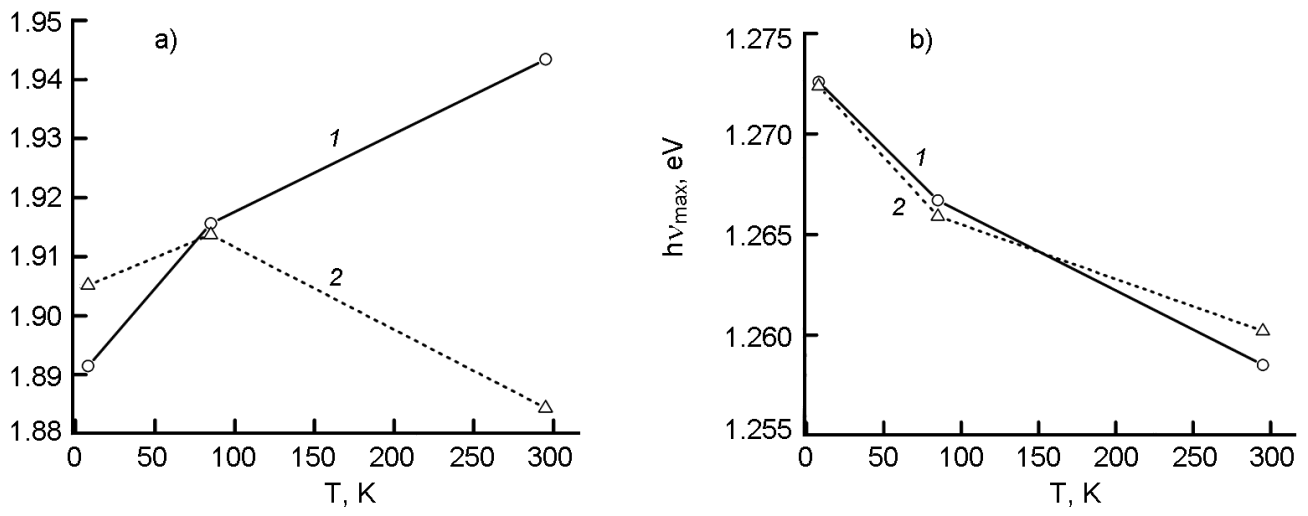

Fig. 2. Spectral position of the maximum of $630 \mathrm{~nm}$ bands (a) and $970 \mathrm{~nm}$ (b) in ZnSe at different temperature (XRL (1) and PL (2)).
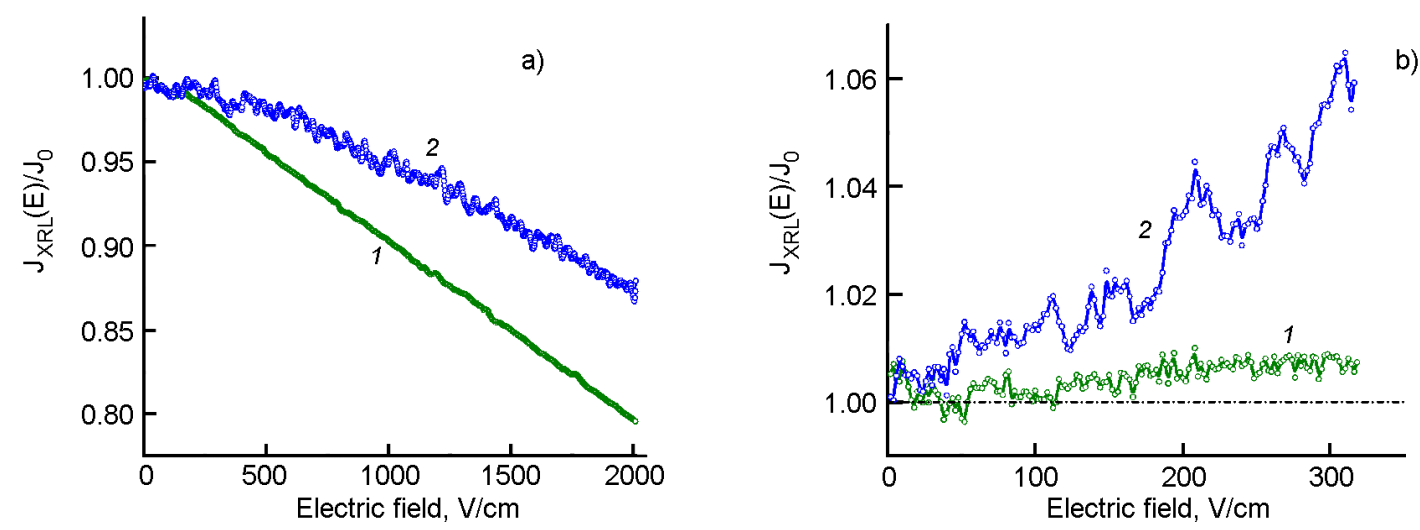

Fig. 3. Influence of external electric field on relative intensity of bands at $630 \mathrm{~nm}$ XRL (1) and $970 \mathrm{~nm}(2)$ in ZnSe at $295 \mathrm{~K}$ (a) and $85 \mathrm{~K} \mathrm{(b).}$

\subsection{Spectral position of the maximum bands at different temperatures}

The spectra of XRL and PL were translated into the scale of energies $\mathrm{eV}$, and the spectral positions of the maxima at different temperatures are shown in Fig. 2. When the temperature increases from $0 \mathrm{~K}$ in all wide band gap semiconductors $A_{2} B_{6}$ decrease of the band gap is revealed. At the same time the quantum energy of luminescence from the centers decreases due to point defects [22]. This situation is observed for the IR band with the maximum at $970 \mathrm{~nm}$. Moreover, the shape of this luminescence band is almost the same for X-ray and photoexcitation across the range of investigated temperatures. A different picture is observed for the band of $630 \mathrm{~nm}$. So, if the spectral position of the maximum of this band upon photoexcitation is not much different from the classical case, when $\mathrm{X}$ ray excitation produced the increase in spectral peak position. This shows, at least, the composition of the luminescence center.

\subsection{Effect of electric field on the lumi- nescence intensity}

In analysis of influence of electric field on the magnitude of the luminescence band intensity it should not be forgotten that the maximum field strength in the sample by external electric field is at least three orders of magnitude less than the magnitude of the electric field between two opposite elementary charges of the adjacent elementary cells of the crystal lattice. Previously it was observed reduction of the luminescence intensity of the band of $630 \mathrm{~nm}$ under the action of external electric field at the room temperature [23]. In this work, measurements of dependence of the intensity of bands at $630 \mathrm{~nm}$ and $970 \mathrm{~nm}$ from the value of the field at different temperatures (Fig. 3) showed that these bands reacted differently to the electric field.

It should be noted that an important feature is the fact that the external electric 
field $(E, \mathrm{kV} / \mathrm{cm})$ can both increase and decrease the luminescence intensity. Since the changes of luminescence intensity are small, then it is logical relative change in the luminescence intensity $J(E) / J_{0}$ be approximated by a straight line and estimated this change in the coefficient of the slope of the line:

$$
k=\frac{J(E) / J_{0}}{E} \cdot\left(V^{-1}\right) .
$$

It should be noted that the coefficient $k$ depends not only on temperature but also on the excitation intensity. Although the nature of this phenomenon is at present not yet established, an important finding is the different behavior of bands at $630 \mathrm{~nm}$ and $970 \mathrm{~nm}$ in the electric field.

Thus, the comparison of characteristics of two dominating recombination selenide zinc strips shows the varying response to the temperature and applied external electric field. Perhaps this indicates the different types of defects causing the appearance of the luminescence bands.

\section{Model of Dipole centers}

There is a simple physical model of the recombination center, which explains the possibility of implementing both mechanisms of recombination. This means that the center in the initial state can be a trap for free electrons and trapped to free holes. As such center offers the Dipole-center model. It would be logical to call such a center as Dipole-center, but as this term is used in other meanings [24, 25], we will call it as Dipole-center. Dipole-center is not a point defect, and is a complex of at least two different defects with opposite local charges, which generate the complex stationary dipole center. Scheme of the Dipolecenter is shown in Fig. 4.

Dipole recombination center is called such an integrated center, which consists of at least two point defects located in neighboring cells of the crystal lattice. This center provides spatial and charge compensation, but one part has the additional positive charge, and the second part is the additional negative charge. This means that this complex in charge-coupled perspective is a dipole. It is not necessarily to additional negative and positive charges are equal. In general, this complex may have net charge different from zero. A characteristic feature of such a center of recombination is the ability to localize in their environment a free electron near a positive charge of the dipole center or locate a spare

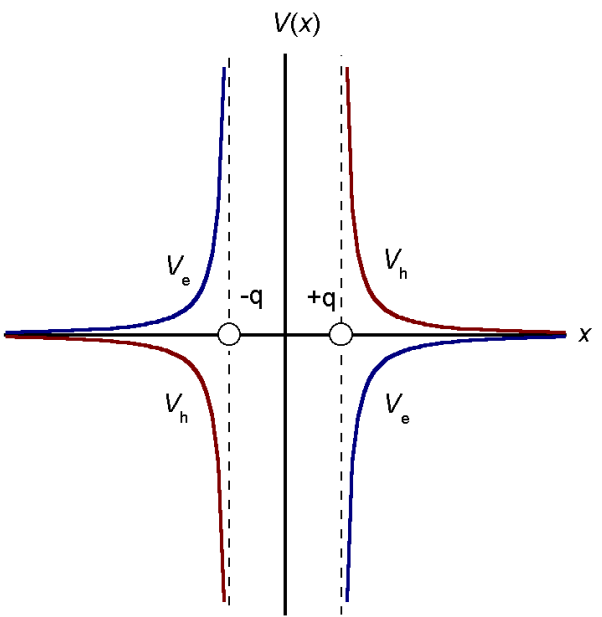

Fig. 4. Scheme of the Dipole-center with potential curves for electrons $\left(V_{e}\right)$ and holes $\left(V_{h}\right)$.

hole near the negative charge. Easily calculate the potential $\left(V_{e}, V_{h}\right)$ for free charge carriers, if: $q^{+}$is the positive charge of the dipole center; $q^{-}-$the negative charge of the center; and $a$ - distance between them. Then for free electron and free hole can be recorded:

$$
\begin{gathered}
V_{e}(x)=-\frac{q^{+}}{4 \pi \varepsilon \varepsilon_{0} a} \cdot \frac{1-\left(\frac{q^{-}}{q^{+}}-1\right) \cdot \frac{x}{a}}{\left(\frac{x}{a}+1\right) \cdot \frac{x}{a}} \text { and } \\
V_{h}(x)=-\frac{q^{-}}{4 \pi \varepsilon \varepsilon_{0} a} \cdot \frac{1-\left(\frac{q^{+}}{q^{-}}-1\right) \cdot \frac{x}{a}}{\left(\frac{x}{a}+1\right) \cdot \frac{x}{a}},
\end{gathered}
$$

where $x$ - distance from the free charge carrier to the charge of the opposite sign of the dipole center; $\varepsilon$ - dielectric constant of the crystal. Since localization of the charge carriers occurs at small distances (up to one or two of the lattice constant), as for excitons of small radius, the dielectric constant is assumed equal to unity. Evaluation of the depth of the localization potentials shows that at distances of order $a=0.567 \mathrm{~nm}$ and the values $q \pm$ of the order of the electron charge, the values of half width of forbidden zone are reached of $1.27 \mathrm{eV}$. This energy decreases with the decreasing of charges and dipole with increasing distance of localization. Thus, this Dipole-center model explains the possibility of the deep localization of electrons and holes.

The possibility of localization of free charge carrier in the vicinity of the center of the dipole center means that the excita- 
tion of the crystal (i.e. in generation of the free electron-hole pairs) the center may first localize, either the free electron or free hole. Following localization of the carrier of the opposite sign leads to their recombination with the emission of a quantum of light. Such centers should also be effective centers of excitons recombination. This means that when significant concentration of the Dipole-centers in the crystal at the low (Helium) temperatures may not be edge glow.

When the charge carrier is placed in the vicinity of the dipole center spatial shift component of an integrated defect has to happen, it is different for cases of localization of the electron or hole. If free carriers of opposite sign are localized, we get different initial spatial configuration of the excited luminescence center. As a result, we have slight differences in the spectra of luminescence at the various recombination mechanisms.

\section{Conclusions}

It is proposed a model of dipole recombination center (Dipole-center), which explains the possibility of realization of two mechanisms of recombination on a single integrated center of luminescence. The experimental results and comparison of characteristics of two centers of luminescence in ZnSe crystals testify that band luminescence with the maximum at $630 \mathrm{~nm}$ and caused by a complex defect give the possibility to apply the model of Dipole-center.

\section{References}

1. A.Sofiienko, V.Degoda, Rad.Meas., 47, 27 (2012).

2. M.Brodin, V.Degoda, B.Kozhushko et al., Rad.Meas., 65, 36 (2014).

3. L.V.Atroshchenko, S.F.Burachas, L.P.Galchinetski et al., Scintillation Crystals and Ionization Radiation Detectors on their Base, Naukova Dumka, Kiev (1998) [in Ukraine].

4. V.Ryzhikov, Scintillation Crystals of Semiconductor Compounds AlIBVI, NIITEHIM, Moscow (1989) [in Russian].
5. V.Ryzhikov, N.Starzhinskiy, K.Katrunov, L.Gal'chinetskii, Functional Materials, 9, 135 (2002).

6. B.Grinyov, V.Ryzhikov, V.Seminozhenko, Scintillation Detectors and Monitoring Systems of Radiation on their Base, Naukova Dumka, Kiev (2007) [in Russian].

7. V.Degoda, N.Pavlova, G.Podust, A.Sofiienko, Physica B: Condens. Matter, 465, 1 (2015).

8. R.Bhargava, R.Seymour, B.Fitzpatrick, S.Herko, Phys. Rev. B, 20, 2407 (1979).

9. V.Ryzhikov, B.Grinyov, S.Galkin et al., $J$. Cryst. Grow., 364, 111 (2013).

10. I.Dafinei, M.Fasoli, F.Ferroni et al., IEEE Trans. Nucl.Sci., 57, 1470 (2010).

11. K.Katrunov, V.Ryzhikov, V.Gavrilyuk et al., Nucl.Inst. Meth. Phys. Res(A), 712, 126 (2013).

12. E.Voronkin, Functional Materials, 21, 1 (2014).

13. E.Gaubas, T.Ceponis, A.Jasiunas et al., J.Phys. D: Appl. Phys., 47, 265102 (2014).

14. V.Koshkin, A.Dulfan, V.Ryzhikov et al., Functional Materials, 8, 708 (2001).

15. G.Watkins, Defects of Lattice in Compounds $\mathrm{A}_{2} \mathrm{~B}_{6}$, in: Book Point Defects of Lattice. 1150 (1979).

16. L.Atroschenko, L.Gal'chinetskii, S.Galkin et al., J.Cryst. Grows, 197, 475 (1999).

17. V.Ryzhikov, N.Starzhinskiy, L.Gal'chinetskii et al., Intern.J.Inorgan. Mater., 8, 1227 (2001).

18. F.Bryant, P.Manning, J.Phys.C, 5, 1914 (1972).

19. N.Morozova, I.Karetnikov, V.Blinov, E.Gavrishchuk, Semiconductors, 35, 512 (2001).

20. D.D.Nedeoglo, A.V.Simashkevich, Electrical and Luminescence Properties of Zinc Selenide, Shtiintsa, Kishinev (1984) [in Russian].

21. H.Waldman, C.Benecke, W.Busse et al., Semicond.Sci. Tehnol., 4, 71 (1989).

22. N.Morozova, I.Karetnikov, V.Blinov, E.Gavrishchuk, Semiconductors, 35, 24 (2001).

23. V.Degoda, A.Sofiienko, Semiconductors, 44, 1 (2010).

24. J.Stathis \& S.Pantelides, Phys.Rev.B, 37, 6579 (1988).

25. S.Huant, S.Najda, B.Etienne, Phys.Rev.Let., 65, 1486 (1990). 